\title{
KEBERADAAN BADAN AKREDITASI PROVINSI SEKOLAH/MADRASAH \\ (UPAYA MENINGKATKAN MUTU PENDIDIKAN MADRASAH DI PROVINSI JAMBI)
}

\author{
M. Syahran Jailani ${ }^{1}$
}

\begin{abstract}
This research is intended to look into the existence of Province Acreditation for School and Islamic School in Jambi through the policies and programs executed, include the result of acreditation for islamic school at Ministry of Religious Affairs in Jambi. The data from Jambi Ministry of Religious Affairs in 2012 showed that from 538 islamic schools which have been acreditated, ie:(a) 244 Islamic Kindergarten, 169 (7,63\%) kindergartens were acreditated, $75(28,37 \%)$ kindergartens were not acreditated, (b). 263 Islamic Elementary School, 171 (61\%) schools were acreditated, 98 $(38,20 \%)$ schools were not acreditated, (c) 345 Islamic Junior High School, $158(44,99 \%)$ schools were acreditated, 187 (55,01\%) schools were not acreditated and (d) 184 Islamic Senior High School, 88 (47,01\%) schools were acreditated and 96 (52,99\%) schools were not acreditated. From 1036 educational institutions, there have been 450 (43,44\%) islamic schools which were acreditated while there were 586 (56,56\%) isclamic schools which were not acreditated. The main problem which happenned was there were many islamic schools got $C$ in acreditation and even some schools were not acreditated. It was caused by: (a) socialization, (b) limitted fund, (c) geographical condition, (d) the low network among islamic schools and (e) there were many policies which have not been accompanied by commitment fully.
\end{abstract}

Keywords : Madrasah/School Acreditation Board, The Quality Of Madrasah Education.

\section{A. Pendahuluan}

Peraturan Pemerintah Nomor 19 Tahun 2005 Pasal 2 ayat (2) tentang Standar Nasional Pendidikan menyatakan bahwa penjaminan dan pengendalian mutu pendidikan yang sesuai dengan Standar Nasional Pendidikan (SNP) perlu dilakukan dalam tiga program

1 Dosen Fakultas Ilmu Tarbiyah \& Keguruan IAIN STS Jambi 
terintegrasi yaitu evaluasi, akreditasi, dan sertifikasi. Penjaminan mutu pendidikan ini bertujuan untuk melindungi masyarakat agar dapat memperoleh layanan dan hasil pendidikan sesuai dengan yang dijanjikan oleh penyelenggara pendidikan. Proses evaluasi terhadap seluruh aspek pendidikan harus diarahkan pada upaya untuk menjamin terselenggaranya layanan pendidikan bermutu dan memberdayakan mereka yang dievaluasi sehingga menghasilkan lulusan pendidikan sesuai standar yang ditetapkan. Standarisasi pendidikan memiliki makna sebagai upaya penyamaan arah pendidikan secara nasional yang mempunyai keleluasaan dan keluwesan dalam implementasinya. Standar Nasional Pendidikan (SNP) harus dijadikan acuan oleh pengelola pendidikan, dan di sisi lain menjadi pendorong tumbuhnya inisiatif dan kreativitas untuk mencapai standar minimal yang ditetapkan.

Penegasan tentang pentingnya akreditasi dapat dilihat pada Undang-undang Nomor 20 Tahun 2003 tentang Sistem Pendidikan Nasional (Sisdiknas), BAB XVI Bagian Kedua Pasal 60, tentang Akreditasi yang berbunyi sebagai berikut: (1) akreditasi dilakukan untuk menentukan kelayakan program dan satuan pendidikan pada jalur pendidikan formal dan nonformal pada setiap jenjang dan jenis pendidikan, (2) akreditasi terhadap program dan satuan pendidikan dilakukan oleh lembaga mandiri yang berwenang sebagai bentuk akuntabilitas publik, (3) akreditasi dilakukan atas dasar kriteria yang bersifat terbuka. (4) ketentuan mengenai akreditasi sebagaimana dimaksud dalam ayat (1), ayat (2), dan ayat (3) diatur lebih lanjut dengan Peraturan Pemerintah.

Proses akreditasi dilakukan secara berkala dan terbuka, dengan tujuan untuk membantu dan memberdayakan program dan satuan pendidikan agar mampu mengembangkan sumber dayanya dalam mencapai tujuan pendidikan nasional. Proses-proses akreditasi dalam pelaksanaannya akan berlangsung manakala segala ketentuan tentang pelaksanaan terpenuhi dengan syarat-syarat, mulai dari pendataan sekolah/madrasah yang belum terakreditasi atau sekolah/madrasah yang telah habis masa akreditasinya sampai ke hasil akhir berdasarkan pleno Badan Akreditasi Sekolah/Madrasah provinsi yang dilakukan setiap tahun. 
Madrasah merupakan salah satu lembaga pendidikan yang bernaung di Kementerian Agama Republik Indonesia. Jauh sebelum bangsa Indonesia merdeka, madrasah-madrasah tersebut telah ada bahkan menjadi awal cikal bakal lahirnya lembaga-lembaga pendidikan Islam sejenis lainnya di Indonesia. Menurut Muhaimin, (2009: 77) salah satu corak pengembangan pendidikan sebelum Indonesia merdeka ialah bercorak isolative-tradisonal, dalam arti tidak mau menerima apa saja yang berbau barat (Kolonial) dan terhambatnya pengaruh pemikiran-pemikiran dalam Islam untuk masuk ke dalamnya, sebagaimana tampak jelas pada pendidikan pondok pesantren tradisional yang hanya menonnjolkan ilmu-ilmu agama Islam dan pengetahuan umum sama sekali tidak diberikan. Pondok pesantren yang merupakan lembaga pendidikan Islam adalah salah satu bentuk lain dari madrasah, jauh lebih dulu hadir sebagai wadah bagi umat Islam untuk belajar dan sebagai tempat untuk mendalami Agama (Islam).

Istilah madrasah diIndonesia, merupakan fenomena modern yang muncul pada awal-awal abad ke-20. Muncul dan berkembangnya madrasah di Indonesia adalah hasil tarik menarik antara pesantren sebagai lembaga pendidikan asli (indegeus cultural/tradisional) yang sudah ada di satu sisi, dengan pendidikan Barat (modern) di sisi lain (Abdul Rachman, 2005: 12) .

Keberadaan madrasah yang tersebar di penjuru bumi Nusantara ini, merupakan hasil insiasi warga masyarakat yang berupaya agar anak-anak mereka dapat memperoleh pendidikan yang layak dan mampu memberikan layanan maksimal terhadap pemenuhan pendidikan mereka, sehingga pada akhirnya anak-anak tersebut menjadi manusia yang berguna, bermanfaat bagi dirinya, keluarga dan bangsanya (Nizar, 2009). Akan tetapi tidak semua madrasahmadrasah yang ada di seluruh penjuru bumi Nusantara ini, telah dan bahkan mampu memberikan layanan dan kebutuhan yang yang menjadi harapan anak-anak, orang tua maupun stakeholder lainnya.

Harus diakui dari jumlah madrasah yang ada, menurut data Direktur Pendidikan Madrasah Dirjen Pendidikan Islam Kementerian Agama RI, jumlah madrasah saat ini mulai dari tingkat aliyah (SMA) dan Tsanawiyah (SMP) berjumlah 58.228 buah, termasuk Raudhatul Athfal (TK) 18,759 lembaga pendidikan Islam. Sudah diakreditasi baru 
sebanyak 9.812, sementara yang belum diakreditasi 48.416 lembaga pendidikan Islam di lingkungan Kementerian Agama Republik Indonesia. Dari 48.416 madrasah yang belum terakreditasi tersebut termasuk madrasah-madrasah yang berada di provinsi Jambi, jika pun terakreditasi sebagian besar dengan predikat akreditasi (C).

Kenyataan tersebut, menuntut semua yang terlibat dalam kelembagaan pendidikan Islam untuk kerja keras melakukan prosesproses pembinaan madrasah-madrasah yang ada melalui lembagalembaga penjaminan mutu. Sebagai bentuk konkrit dari upaya kerja keras tersebut, Badan Akreditasi Sekolah/Madrasah (BAP S/M) Provinsi Jambi sebagai lembaga independen yang bertugas melakukan proses penjaminan mutu, melalui mekanisme dan petunjuk teknis telah dan akan terus melakukan proses Akreditasi berdasarkan pemetaan pada masing-masing satuan pendidikan yang dikelola Kementerian Agama Provinsi Jambi maupun Kementerian Agama Kabupaten/Kota.

Berbicara peningkatan mutu sebaiknya kita membahas sekilas tentang mutu. Istilah Mutu berasal dari bahasa Latin, "Qualis", yang artinya what kind of. Mutu adalah kesesuaian dengan kebutuhan pasar. Menurut Juran, ialah kecocokan dengan produk. Menurut Crosby ialah kesesuaian dengan yang disyaratkan. Menurut West-Burnham ialah ukuran relatif suatu produk atas jasa sesuai dengan standar mutu desain (dalam Husaini Usman, 2006: 407-408).

Sallis $(2010,53)$ mendefinisikan mutu sebagai suatu konsep yang relatif. Definisi relatif tersebut memandang mutu bukan sebagai suatu atribut produk atau layanan, tetapi sesuatu yang dianggap berasal dari produk atau layanan tersebut. Mutu dapat dikatakan ada apabila sebuah layanan memenuhi spesifikasi yang ada. Mutu merupakan sebuah cara yang menentukan apakah produk terakhir sesuai dengan standar atau belum. Produk atau layanan yang memiliki mutu, dalam konsep relatif tidak harus mahal atau eksklusif. Produk layanan tidak harus spesial, tapi harus asli, wajar, dan familiar. Proyektor jinjing, pena ballpoint, dan layanan cattering sekolah bisa dikatakan bermutu jika memang telah memenuhi standar. Sehingga, mutu harus mengerjakan apa yang seharusnya ia kerjakan, dan mengerjakan apa yang diinginkan pelanggan. Dengan kata lain, ia harus sesuai dengan tujuannya. 
Mutu dapat pula didefinisikan sebagai sesuatu yang memuaskan dan melampaui keinginan dan kebutuhan pelanggan. Atau disebut juga dengan istilah mutu sesuai dengan persepsi (quality in perseption). Mutu ini bisa disebut sebagai mutu yang hanya ada di mata orang yang melihatnya. Artinya, bahwa pelanggan adalah pihak yang membuat keputusan terhadap mutu. Dan mereka melakukan penilaian tersebut dengan merujuk pada produk terbaik yang bisa bertahan dalam persaingan (Sallis, 2010: 56).

Menurut Husaini (2006: 411) pesan yang ingin disampaikan mutu antara lain, yaitu: (a) kita mengenal mutu, jika kita telah mengenalnya, (b) mutu adalah kepuasan sehingga sulit untuk menjelaskannya, (c) dalam kehidupan dan penghidupan kita ingin yang bermutu karena kodrat manusia yang normal adalah ingin menuju kepada kesempurnaan, (d) ketika kita merasa tidak mungkin mencapai mutu atau gagal mencapai mutu, kita lalu meremehkannya, (e) ada anggapan mutu identik dengan biaya tinggi, tenaga terlatih, dan waktu yang lama, (f) mutu membedakan yang satu dengan yang lain, (g) organisasi yang terbaik, baik pemerintah maupun perusahaan swasta memahami mutu itu penting dan mengetahuinya sebagai sesuatu yang tersembunyi dan kadang-kadang dirahasiakan menjadi rahasia perusahaan, (h) mencari sumber mutu adalah sesuatu yang sangat penting, (i) mutu mudah diucapkan, tetapi sulit untuk diwujudkan, (j) bekerja secara profesional, (k) mutu untuk meningkatkan akuntabilitas sekolah, (l) mutu untuk menjamin kualitas input, proses, produk, dan outcome sekolah.

Selanjuntnya menurut Husaini (2006: 411-413) mutu memiliki 13 karakteristik, sebagai berikut: (a) kinerja (performa), (b) waktu wajar (timeliness), (c) handal (reability), (d) daya tahan (durability), (e) indah (aestetics), (f) hubungan manusiawi ( personal interface), (g) mudah penggunaannya ( easy of use), (h) bentuk khusus (feature), (i) standar tertentu (comformance to specification), (j) konsistensi (Consistency), (k) seragam (uniformity), (l) mampu melayani (serviceability), (m) ketepatan (acuracy).

Selanjutnya, berdasarkan latar belakang masalah dan batasan masalah di atas, penelitian ini akan menfokuskan masalah pada tiga hal, yaitu; (a) bagaimana hasil pelaksanaan akreditasi madrasah di Provinsi Jambi? (b) apa saja problem utama pelaksanaan akreditasi 
madrasah dalam meningkatkan mutu pendidikan di Provinsi Jambi?

(c) bagaimana pula dukungan stakeholder terhadap pelaksanaan akreditasi madrasah dalam meningkatkan mutu pendidikan di Provinsi Jambi?

Adapun tujuan dari penelitian ini diharapkan dapat menggali lebih dalam tentang, yaitu: (a) untuk mengetahui secara komprehensif hasil akhir pelaksanaan akreditasi madrasah di Provinsi Jambi? (b) untuk mengungkap apa saja problem utama pelaksanaan Akreditasi madrasah dan untuk mengetahui dukungan stakeholder terhadap pelaksanaan akreditasi madrasah dalam meningkatkan mutu pendidikan Provinsi Jambi?

Penelitian ini sangat bermanfaat bagi stakeholder dalam upaya peningkatan sumber daya manusia Indonesia. Khususnya manfaat penelitian ini tentunya berkonstribusi, yaitu: (a) bagi peneliti; sebagai khazanah ilmu pengetahuan dan pengembangan wawasan ilmiah dalam rangka penguatan disiplin ilmu, (b) bagi madrasah; akan menjadi informasi dan masukan yang berharga dalam rangka meningkatkan mutu madrasah dan pendidikan umumnya, (c) bagi institusi / lembaga pendidikan; sebagai upaya awal pemetaan, tentang kondisi ke-kinian pendidikan di bawah lingkungan Kementerian Departemen Agama Provinsi Jambi, bagi peningkatan sumber daya manusia melalui dunia pendidikan. Dan juga dapat dijadikan referensi/rujukan dalam upaya memberikan solusi konkrit terhadap problema dunia pendidikan terutama berkaitan kelembagaan Pendidikan Islam.

\section{B. Metode Penelitian}

Penelitian ini dilakukan dengan menggunakan pendekatan mixing method (Creswell, 2008: 552), dengan pertimbangan yaitu: data kualitatif digunakan untuk memahami dan mendalami temuan sehingga data menjadi terpecaya. Sementara, data kuantitatif diperlukan untuk mendukung temuan lapangan sebagai data pembanding. Di samping itu pula, data kuantitatif digunakan untuk mengambarkan data secara sederhana tantang hasil visitasi sekolah/ madrasah yang dilakukan para asesor yang bertugas.

Teknik pengambilan sampel yang digunakan adalah Snowball sampling. Metode pengumpulan data yang digunakan dalam penelitian ini yaitu observasi, wawancara, dokumentasi dan menggunakan 
sumber non manusia, serta pencatatan hasil pengumpulan data. Didukung pula oleh interaksi langsung dengan subjek peneliti seperti, mendengarkan, melihat, berbicara, bertanya, meminta penjelasan, mengekspresikan dan menangkap isyarat yang tersirat dari subjek yang terlibat, (Denzin dan Lincoln, 2009: 504-525)

Untuk menjamin keabsahan data, mengacu pada Lincoln dan Guba (1985: 328-332), yaitu : 1) standar kredibilitas. dapat dilakukan, yaitu: (a) teknik triangulasi. Triangulasi dilakukan agar informasi yang terkumpul dan diterima memiliki keakuratan data. Bogdan dan Biklen (1992), Moleong (1991), dan Sugiono (2007:373) menyarankan dilaksanakan triangulasi data dengan cara, yaitu; 1) Triangulasi sumber data yaitu membandingkan data atau mengecek kembali derajat kepercayaan suatu informasi yang diperoleh melalui beberapa sumber, 2) triangulasi waktu, yaitu untuk menguji derajat kepercayaan dengan mengecek data kepada sumber yang sama dalam waktu atau situasi yang berbeda. Hal ini dilakukan untuk menilai apakah waktu/situasi mempengaruhi informan dalam menyajikan data; 3) triangulasi metode/teknik yaitu menguji derajat kepercayaan dengan cara mengecek data kepada sumber yang sama dengan teknik yang berbeda. 2) standar tranferbilitas. Untuk mendapatkan gambaran yang konkrit dan jelas tentang konteks apa yang dihasilkan dari penelitian ini, maka diusahakan dengan memperbanyak uraian rincian tentang latar dan fokus penelitian. Tujuan dari uraian dimaksud untuk merinci secara sistematis dan terarah. Dan ini dibuat pada catatan lapangan penelitian. 3) standar dependabilitas. Standar dependabilitas dilakukan untuk mengecek benar-salah hal-hal yang peneliti konseptualisasikan apa yang diteliti. Untuk memperoleh standar ini, diusahakan sedapat mungkin konsisten dalam proses pengumpulan, menginterpretasikan temuan, dan melaporkan hasil penelitian (Lexy, 2007:339). 4) standar konfirmabilitas. Kualitas hasil penelitian sangat bergantung dari catatan data lapangan dan hasil observasi yang mendalam serta didukung rekaman yang dilakukan peneliti.

\section{Hasil dan Pembahasan}

\section{Hasil Penelitian}

Sejak perubahan Badan Akreditasi Sekolah (BAS) Provinsi, menjadi Badan Akreditasi Sekolah/Madrasah (BAS S/M) Provinsi 
pada tahun 2007, Terjadi penyatuan lembaga pendidikan yang melakukanakreditasi sekolah/madrasah.Jika lembaga akreditasi yang dikelola Kementerian Agama Republik Indonesia yang sebelumnya bernama Dewan Akreditasi Madrasah (DAM), melakukan proses akreditasi madrasah dengan menggunakan instrumen tersendiri, sementara di Kementerian Pendidikan Nasional Republik Indonesia lembaga akreditasi bernama Badan Akreditasi Sekolah (BAS) Provinsi melakasanakan proses akreditasi dengan instrumen tersendiri pula. Maka sejak tahun 2007, melalui Keputusan Menteri Pendidikan Nasional Nomor 29 tahun 2005, tentang Badan Akreditasi Nasional Sekolah/Madrasah (BAN S/M) pada Pasal 16 ayat (1 dan 2), menyatakan bahwa BAP S/M adalah Badan evaluasi mandiri yang menetapkan kelayakan program dan/atau satuan pendidikan, jenjang pendidikan dasar, menengah pada jalur formal. Peraturan Pemerintah Nomor 19 tahun 2005 tentang Standar Nasional Pendidikan, lembaga yang secara khusus melakukan akreditasi sekolah/madrasah mulai dari Taman kanak-kanak (TK) / Raudhatul Athfal (RA), Sekolah Dasar (SD)/ Madrasah Ibtidaiyah (MI), Sekolah Menengah Pertama (SMP) /Madrasah Tsanawiyah (MTs), dan Sekolah Menengah Atas (SMA)/ Madrasah Aliyah (MA).

Tabel. 1: Hasil sebaran akreditasi Sekolah/Madrasah tahun 2012/2013

REALISASI PELAKSANAAN AKREDITASI

SEKOLAH/MADRASAH TAHUN 2012

\begin{tabular}{|c|c|c|c|c|}
\hline No & Jenjang & Rencana & Realisasi & Prosentase \\
\hline 1 & TK & 27 & 27 & $5.02 \%$ \\
\hline 2 & RA & 3 & 3 & $0.56 \%$ \\
\hline 3 & $S D$ & 29.3 & 29.3 & $54.46 \%$ \\
\hline 4 & $\mathrm{Ml}$ & 17 & 17 & $3.16 \%$ \\
\hline 5 & SMP & 63 & 63 & $11.71 \%$ \\
\hline 6 & MTs & 28 & 25 & $4.65 \%$ \\
\hline 7 & SMA & 18 & 17 & $3.16 \%$ \\
\hline 8 & MA & 36 & 28 & $5.20 \%$ \\
\hline 9 & $\left.\mathrm{SMK}^{*}\right)$ & 51 & 45 & $8.36 \%$ \\
\hline 10 & SLB/SDLB $\left.{ }^{\star *}\right)$ & 2 & 2 & $0.37 \%$ \\
\hline & Jumlah & 538 & 520 & $96.65 \%$ \\
\hline
\end{tabular}

Keterangan *) Kompetensi Keahlian **) Program 
Berdasakan rencana pelaksanaan akreditasi tahun 2012, dari 538 sekolah dan madrasah yang akan diakreditasi berdasarkan data/usulan Unit Pelaksan Akreditasi (UPA) Sekolah/Madrasah Kabupaten/Kota dalam Provinsi Jambi, yang terealisasi sekolah/ madrasah se-provinsi Jambi berjumlah 520 sekolah/madrasah, yang tersebar di 11 (sebelas) Kabupaten/Kota (lihat tabel, 1).

Dari realisasi 520 seolah/madrasah yang yang melakukan proses akreditasi oleh Badan Akreditasi Provinsi (BAP-S/M) Jambi, lembaga pendidikan berupa madrasah-madrasah di bawah pengelolaan Kementerian Agama Republik Indonesia, memperoleh quota untuk diakreditasi sebanyak 73 madrasah. Dengan rincian, 3 buah Raudhatul Athfal, 17 Madrasah Ibtidaiyah, 25 Madrasah Tsanawiyah, dan 28 Madrasah Aliyah, (Data BAP S/M Jambi, 2013).

Tabel. 2: Sebaran akreditasi Sekolah/

Madrasah berdasarkan TK/RA 2012/2013

DISTRIBUSI PERINGKAT AKREDITASI TK/RA TAHUN 2012

\begin{tabular}{|l|l|l|l|l|l|l|l|l|l|l|l|}
\hline \multirow{2}{*}{ No } & \multirow{2}{*}{$\begin{array}{l}\text { Kabupaten/ } \\
\text { Kota }\end{array}$} & \multicolumn{9}{|c|}{ TK } & \multicolumn{5}{|c|}{ RA } \\
\cline { 3 - 13 } & A & B & C & TT & JLH & A & B & C & TT & JLH \\
\hline 1 & Kota Jambi & 2 & 1 & 0 & 0 & 3 & 0 & 0 & 0 & 0 & 0 \\
\hline 2 & Batanghari & 0 & 1 & 1 & 0 & 2 & 0 & 0 & 0 & 1 & 1 \\
\hline 3 & Muaro Jambi & 1 & 1 & 1 & 0 & 3 & 0 & 0 & 0 & 0 & 0 \\
\hline 4 & Tanjab Timur & 0 & 1 & 1 & 1 & 3 & 0 & 0 & 0 & 0 & 0 \\
\hline 5 & Tanjab Barat & 0 & 1 & 2 & 0 & 3 & 0 & 0 & 0 & 0 & 0 \\
\hline 6 & Tebo & 0 & 1 & 2 & 0 & 3 & 0 & 0 & 0 & 0 & 0 \\
\hline 7 & Bungo & 1 & 0 & 1 & 0 & 2 & 1 & 0 & 0 & 0 & 1 \\
\hline 8 & Sarolangun & 0 & 1 & 2 & 0 & 3 & 0 & 0 & 0 & 0 & 0 \\
\hline 9 & Merangin & 0 & 1 & 1 & 0 & 2 & 0 & 0 & 0 & 1 & 1 \\
\hline 10 & Kerinci & 0 & 1 & 2 & 0 & 3 & 0 & 0 & 0 & 0 & 0 \\
\hline 11 & $\begin{array}{l}\text { Sungai } \\
\text { Penuh }\end{array}$ & 0 & 0 & 0 & 0 & 0 & 0 & 0 & 0 & 0 & 0 \\
\hline Jumlah & 4 & 9 & 13 & 1 & 27 & 1 & 0 & 0 & 2 & 3 \\
\hline \multicolumn{2}{|l|}{ Persentase } & 14,81 & 33,33 & 48,15 & 3,70 & 100 & 33,33 & 0,00 & 0,00 & 66,67 & 100 \\
\hline
\end{tabular}

Data di atas, menunjukan bahwa dari 3 Raudhatul Athfal yang diakreditasi, hanya 1 Raudhatul Athfal memperoleh akreditasi (A), sedang akretiasi (B) untuk Raudhatul Athfal belum terpenuhi, dan 2 Raudhatul Athfal tidak terakreditasi (TT).

Sementara itu, untuk madrasah Ibtidaiyah dari 17 madrasah Ibtidaiyah yang dilakukan proses akreditasi, hanya 1 Madrasah 
Ibtidaiyah memperoleh akreditasi (A), 5 Madrasah Ibtidaiyah terakreditasi (B), 7 Madrasah Ibtidaiyah terakreditasi (C), dan 4 Madrasah Ibtidaiyah tidak terakreditasi (TT). (lihat tabel. 3 di bawah ini).

Tabel. 3: Sebaran hasil akreditasi Sekolah/Madrasah timgkat SD/ MI 2012/2013

DISTRIBUSI PERINGKAT AKREDITASI SD/MI TAHUN 2012

\begin{tabular}{|l|l|l|l|l|l|l|l|l|l|l|l|}
\hline \multirow{2}{*}{ No } & \multirow{2}{*}{$\begin{array}{c}\text { Kabupaten/ } \\
\text { Kota }\end{array}$} & \multicolumn{9}{|c|}{ SD } & \multicolumn{6}{|c|}{ MI } \\
\cline { 3 - 13 } & A & \multicolumn{1}{|c|}{ C } & C & TT & JLH & A & B & C & D & JLH \\
\hline 1 & Kota Jambi & 9 & 14 & 5 & 0 & 28 & 1 & 1 & 0 & 0 & 2 \\
\hline 2 & Batanghari & 1 & 18 & 18 & 0 & 37 & 0 & 0 & 0 & 0 & 0 \\
\hline 3 & Muaro Jambi & 1 & 10 & 24 & 0 & 35 & 0 & 0 & 4 & 1 & 5 \\
\hline 4 & Tanjab Timur & 0 & 0 & 2 & 0 & 2 & 0 & 0 & 0 & 0 & 0 \\
\hline 5 & Tanjab Barat & 0 & 14 & 19 & 0 & 33 & 0 & 1 & 2 & 1 & 4 \\
\hline 6 & Tebo & 1 & 12 & 19 & 2 & 34 & 0 & 0 & 1 & 0 & 1 \\
\hline 7 & Bungo & 3 & 26 & 6 & 0 & 35 & 0 & 3 & 0 & 2 & 5 \\
\hline 8 & Sarolangun & 0 & 10 & 10 & 0 & 20 & 0 & 0 & 0 & 0 & 0 \\
\hline 9 & Merangin & 0 & 0 & 7 & 2 & 9 & 0 & 0 & 0 & 0 & 0 \\
\hline 10 & Kerinci & 3 & 16 & 13 & 0 & 32 & 0 & 0 & 0 & 0 & 0 \\
\hline 11 & Sungai Penuh & 1 & 22 & 5 & 0 & 28 & 0 & 0 & 0 & 0 & 0 \\
\hline Jumlah & 19 & 142 & 128 & 4 & 293 & 1 & 5 & 7 & 4 & 17 \\
\hline Persentase & 6,48 & 48,46 & 43,69 & 1,37 & 100 & 5,88 & 29,41 & 41,18 & 23,53 & 100 \\
\hline
\end{tabular}

Untuk Madrasah Tsanawiyah, dari proses akreditasi sebanyak 25 madrasah se-Provinsi Jambi yang tersebar di 11 kabupaten/Kota, hasil peringkat akreditasi (A) sebanyak 2 Madrasah Tsanawiyah, 11 Madrasah Tsanawiyah akreditasi (B), 9 Madrasah Tsanawiyah akreditasi (C), dan 3 Madrasah Tsanawiyah tidak terakreditasi TT). Sebaran nilai akreditasi berdasarkan madrasah per-Kabupaten/Kota dan peringkat akreditasi dapat di lihat tabel. 4 berikut ini:

Tabel. 4: Sebaran hasil akreditasi Sekolah/Madrasah SMP/MTs 2012/2013

DISTRIBUSI PERINGKAT AKREDITASI SMP/MTs TAHUN 2012

\begin{tabular}{|l|l|l|l|l|l|l|l|l|l|l|l|}
\hline \multirow{2}{*}{ No } & Kabupaten/ & \multicolumn{5}{|c|}{ SMP } & \multicolumn{5}{|c|}{ MTs } \\
\cline { 3 - 13 } & Kota & A & B & C & TT & JLH & A & B & C & D & JLH \\
\hline 1 & $\begin{array}{l}\text { Kota } \\
\text { Jambi }\end{array}$ & 1 & 5 & 1 & 0 & 7 & 1 & 2 & 0 & 0 & 3 \\
\hline 2 & Batanghari & 0 & 5 & 0 & 0 & 5 & 0 & 1 & 1 & 0 & 2 \\
\hline
\end{tabular}




\begin{tabular}{|l|l|l|l|l|l|l|l|l|l|l|l|}
\hline 3 & $\begin{array}{l}\text { Muaro } \\
\text { Jambi }\end{array}$ & 6 & 3 & 0 & 0 & 9 & 0 & 2 & 2 & 1 & 5 \\
\hline 4 & $\begin{array}{l}\text { Tanjab } \\
\text { Timur }\end{array}$ & 0 & 4 & 2 & 0 & 6 & 0 & 3 & 0 & 0 & 3 \\
\hline 5 & $\begin{array}{l}\text { Tanjab } \\
\text { Barat }\end{array}$ & 0 & 2 & 5 & 0 & 7 & 0 & 0 & 2 & 2 & 4 \\
\hline 6 & Tebo & 0 & 5 & 3 & 0 & 8 & 0 & 0 & 2 & 0 & 2 \\
\hline 7 & Bungo & 3 & 3 & 0 & 0 & 6 & 1 & 1 & 0 & 0 & 2 \\
\hline 8 & Sarolangun & 0 & 2 & 1 & 0 & 3 & 0 & 1 & 1 & 0 & 2 \\
\hline 9 & Merangin & 0 & 1 & 1 & 3 & 5 & 0 & 1 & 1 & 0 & 2 \\
\hline 10 & Kerinci & 1 & 0 & 6 & 0 & 7 & 0 & 0 & 0 & 0 & 0 \\
\hline 11 & $\begin{array}{l}\text { Sungai } \\
\text { Penuh }\end{array}$ & 0 & 0 & 0 & 0 & 0 & 0 & 0 & 0 & 0 & 0 \\
\hline Jumlah & 11 & 30 & 19 & 3 & 63 & 2 & 11 & 9 & 3 & 25 \\
\hline Persentase & 17,46 & 47,62 & 30,16 & 4,76 & 100 & 8,00 & 44,00 & 36,00 & 12,00 & 100 \\
\hline
\end{tabular}

Sementara itu, untuk tahun 2012 madrasah Aliyah se-Provinsi Jambi mendapat quota sebanyak 28 Madrasah Aliyah untuk dilakukan proses akreditasi, yang tersebar di 11 Kabupaten / Kota. Dari 28 Madrasah Aliyah tersebut, tidak ada yang terakreditasi (A), hanya 5 Madrasah Aliyah terakreditasi (B), 15 Madrasah Aliyah terakreditasi (C), dan 8 Madrasah Aliyah tidak terakreditasi (TT). Sebaran peringkat madrasah Aliyah per-Kabupaten/Kota tergambar pada table 5 berikut di bawah ini:

Tabel. 5: Sebaran hasil akreditasi Sekolah/Madrasah jenjang SMA/MA 2012/2013

DISTRIBUSI PERINGKAT AKREDITASI SMA/MA TAHUN 2012

\begin{tabular}{|c|c|c|c|c|c|c|c|c|c|c|c|}
\hline \multirow{2}{*}{ No } & \multirow{2}{*}{$\begin{array}{c}\text { Kabupaten/ } \\
\text { Kota }\end{array}$} & \multicolumn{5}{|c|}{ SMA } & \multicolumn{5}{|c|}{ MA } \\
\hline & & A & B & C & TT & JLH & A & B & $\mathrm{C}$ & D & JLH \\
\hline 1 & Kota Jambi & 0 & 1 & 0 & 0 & 1 & 0 & 0 & 4 & 0 & 4 \\
\hline 2 & Batanghari & 0 & 0 & 1 & 0 & 1 & 0 & 0 & 1 & 0 & 1 \\
\hline 3 & $\begin{array}{l}\text { Muaro } \\
\text { Jambi }\end{array}$ & 0 & 0 & 0 & 0 & 0 & 0 & 0 & 0 & 0 & 0 \\
\hline 4 & \begin{tabular}{|l|} 
Tanjab \\
Timur
\end{tabular} & 0 & 1 & 0 & 0 & 1 & 0 & 1 & 3 & 2 & 6 \\
\hline 5 & $\begin{array}{l}\text { Tanjab } \\
\text { Barat }\end{array}$ & 0 & 0 & 2 & 0 & 2 & 0 & 0 & 1 & 0 & 1 \\
\hline 6 & Tebo & 0 & 2 & 1 & 0 & 3 & 0 & 2 & 1 & 1 & 4 \\
\hline 7 & Bungo & 1 & 1 & 0 & 1 & 3 & 0 & 1 & 2 & 1 & 4 \\
\hline 8 & Sarolangun & 1 & 2 & 0 & 1 & 4 & 0 & 0 & 1 & 3 & 4 \\
\hline 9 & Merangin & 0 & 2 & 0 & 0 & 2 & 0 & 0 & 2 & 1 & 3 \\
\hline 10 & Kerinci & 0 & 0 & 0 & 0 & 0 & 0 & 1 & 0 & 0 & 1 \\
\hline
\end{tabular}




\begin{tabular}{|c|c|c|c|c|c|c|c|c|c|c|c|}
\hline 11 & \begin{tabular}{|l|} 
Sungai \\
Penuh
\end{tabular} & 0 & 0 & 0 & 0 & 0 & 0 & 0 & 0 & 0 & 0 \\
\hline \multicolumn{2}{|c|}{ Jumlah } & 2 & 9 & 4 & 2 & 17 & 0 & 5 & 15 & 8 & 28 \\
\hline \multicolumn{2}{|c|}{ Persentase } & 11,76 & 52,94 & 23,53 & 11,76 & 100 & 0,00 & 17,86 & 53,57 & 28,57 & 100 \\
\hline
\end{tabular}

Data di atas menunjukan bahwa, hasil pemeringkatan akreditasi madrasah Aliyah Provinsi Jambi, sebagian besar hanya akreditasi (C) dan tidak terakreditasi (TT) yang tersebar di 11 kabupaten/ Kota. Dari data juga, mengindikatorkan umumnya Madrasah Aliyah yang terakreditasi (C) dan tidak terakreditasi (TT) adalah madrasahmadrasah Swasta yang tersebar di pelosok pedesaan. (Sumber Data, BAP-S/M Jambi: 2013)

\section{Tabel. 6: Sebaran akreditasi Sekolah/Madrasah berdasarkan peringkat}

\section{HASIL AKREDITASI BERDASARKAN PERINGKAT TAHUN 2012}

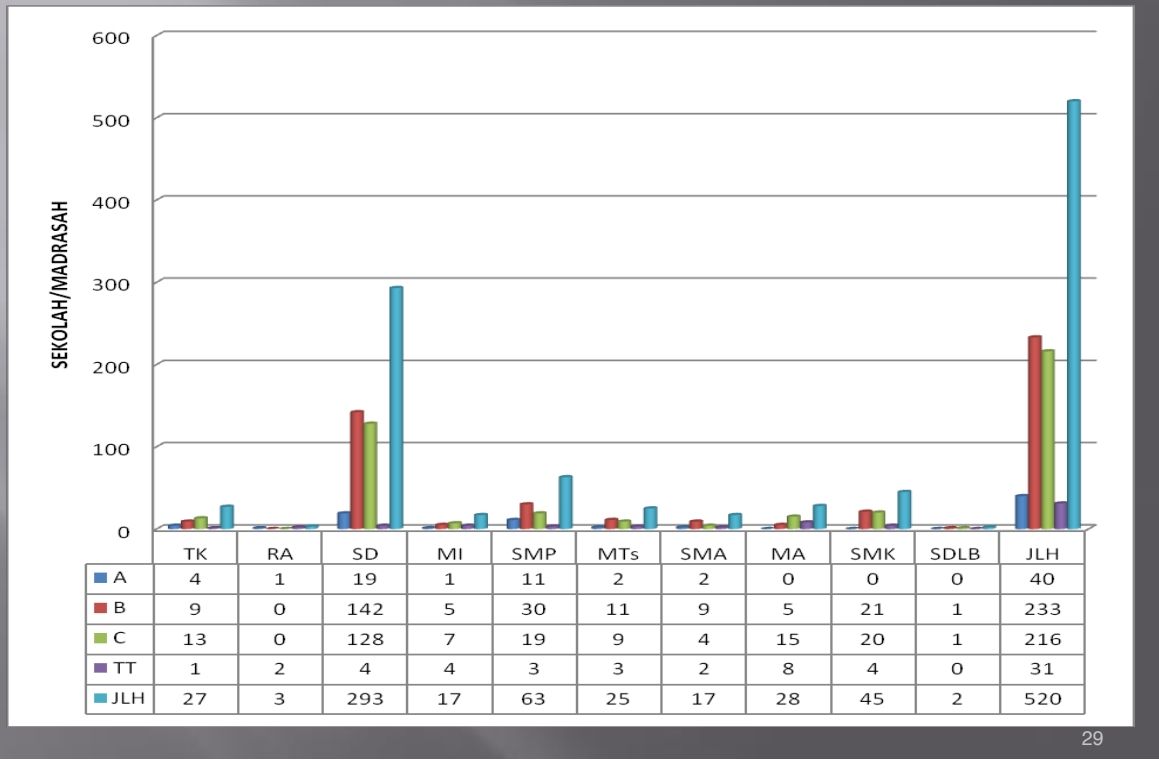

Data tabel di atas menggambarkan bahwa, lembaga pendidikan di bawah Kementerian Agama Republik Indonesia khususnya di Kementerian Agama Provinsi Jambi, masih banyak madrasahmadrasah yang belum terakreditasi, bahkan ada madrasah yang belum siap untuk diakreditasi. 
Tabel. 7 : Realisasi Akreditasi Madrasah Raudhatul Athfal (RA) Kementerian Agama Provinsi Jambi berdasar prosentase REKAP AKREDITASI MADRASAH DI LINGKUNGAN KANWIL KEMENTERIAN AGAMA PROVINSI JAMBI TAHUN 2012

\begin{tabular}{|c|c|c|c|c|c|c|}
\hline \multirow{3}{*}{ No } & \multirow{3}{*}{ КАВ/КОТА } & \multirow{3}{*}{$\mathbf{R A}$} & \multicolumn{4}{|c|}{ AKREDITASI RA } \\
\hline & & & \multicolumn{2}{|c|}{ SUDAH } & \multicolumn{2}{|c|}{ BELUM } \\
\hline & & & BAP & $\%$ & BLM & $\%$ \\
\hline 1. & Kota Jambi & 39 & 16 & 41,03 & 23 & $\mathbf{5 8 , 9 7}$ \\
\hline 2. & Muaro Jambi & 16 & 4 & 25,00 & 12 & 75,00 \\
\hline 3. & Batang Hari & 13 & 4 & 30,77 & 9 & 69,23 \\
\hline 4. & Tebo & 38 & 19 & 50,00 & 19 & 50,00 \\
\hline 5. & Bungo & 43 & 13 & 30,23 & 30 & 69,77 \\
\hline 6. & Sarolangun & 14 & 5 & 35,71 & 9 & 64,29 \\
\hline 7. & Merangin & 36 & 9 & 25,00 & 27 & 75,00 \\
\hline 8. & Kerinci & 30 & 2 & 6,67 & 28 & 93,33 \\
\hline 9. & Tanjab Barat & 7 & 1 & 14,29 & 6 & 85,71 \\
\hline 10. & Tanjab Timur & 8 & 2 & 25,00 & 6 & 75,00 \\
\hline & JUMLAH & 244 & 75 & 28,37 & 169 & 71,63 \\
\hline
\end{tabular}

Data di atas mengindikasikan bahwa, sampai tahun 2012, dari 244 Raudhatul Athfal yang diakreditasi hanya 75 (RA) atau 28,37\% yang sudah terakreditasi, 169 atau $71,63 \%$ belum terakreditasi. 
Tabel. 8: Realisasi Akreditasi Madrasah Ibtidaiyah berdasarkan prosentase

\begin{tabular}{|c|c|c|c|c|c|c|}
\hline \multirow{3}{*}{ No } & \multirow{3}{*}{ КАВ/КОТА } & \multirow{3}{*}{ MI } & \multicolumn{4}{|c|}{ AKREDITASI MI } \\
\hline & & & \multicolumn{2}{|c|}{ SUDAH } & \multicolumn{2}{|c|}{ BELUM } \\
\hline & & & BAP & $\%$ & BLM & $\%$ \\
\hline 1. & Kota Jambi & 34 & 4 & 11,76 & 30 & 88,24 \\
\hline 2. & Muaro Jambi & 24 & 18 & 75,00 & 6 & 25,00 \\
\hline 3. & Batang Hari & 10 & 3 & 30,00 & 7 & 70,00 \\
\hline 4. & Tebo & 31 & 17 & 54,84 & 14 & 45,16 \\
\hline 5. & Bungo & 24 & 7 & 29,17 & 17 & 70,83 \\
\hline 6. & Sarolangun & 16 & 9 & 56,25 & 7 & 43,75 \\
\hline 7. & Merangin & 21 & 5 & 23,81 & 16 & 76,19 \\
\hline 8. & Kerinci & 50 & 8 & 16,00 & 42 & 84,00 \\
\hline 9. & Tanjab Barat & 30 & 6 & 20,00 & 24 & 80,00 \\
\hline 10. & Tanjab Timur & 23 & 15 & 65,22 & 8 & 34,78 \\
\hline & JUMLAH & 263 & 92 & 38,20 & 171 & 61,80 \\
\hline
\end{tabular}

Tabel. 9: Realisasi Akreditasi Madrasah Tsanawiyah berdasar $\%$

\begin{tabular}{|c|c|c|c|c|c|c|}
\hline \multirow{3}{*}{ No } & \multirow{3}{*}{ КАВ/КОТА } & \multirow{3}{*}{ MTs } & \multicolumn{4}{|c|}{ AKREDITASI MTS } \\
\hline & & & \multicolumn{2}{|c|}{ SUDAH } & \multicolumn{2}{|c|}{ BELUM } \\
\hline & & & BAP & $\%$ & BLM & $\%$ \\
\hline 1. & Kota Jambi & 32 & 16 & 50,00 & 16 & 50,00 \\
\hline 2. & Muaro Jambi & 38 & 22 & 57,89 & 16 & 42,11 \\
\hline 3. & Batang Hari & 30 & 14 & 46,67 & 16 & 53,33 \\
\hline 4. & Tebo & 38 & 30 & 78,95 & 8 & 21,05 \\
\hline 5. & Bungo & 29 & 18 & 62,07 & 11 & 37,93 \\
\hline 6. & Sarolangun & 40 & 29 & 72,50 & 11 & 27,50 \\
\hline 7. & Merangin & 35 & 21 & 60,00 & 14 & 40,00 \\
\hline 8. & Kerinci & 23 & 14 & 60,87 & 9 & 39,13 \\
\hline 9. & Tanjab Barat & 49 & 11 & 22,45 & 38 & $\mathbf{7 7 , 5 5}$ \\
\hline 10. & Tanjab Timur & 31 & 12 & 38,71 & 19 & 61,29 \\
\hline & JUMLAH & 345 & 187 & 55,01 & 158 & 44,99 \\
\hline
\end{tabular}


Tabel. 10: Realisasi Akreditasi Madrasah Aliyah berdasarkan prosentase

\begin{tabular}{|c|c|c|c|c|c|c|}
\hline \multirow{3}{*}{ No } & \multirow{3}{*}{ KАВ/КОТА } & \multirow{3}{*}{ MA } & \multicolumn{4}{|c|}{ AKREDITASI MA } \\
\hline & & & \multicolumn{2}{|c|}{ SUDAH } & \multicolumn{2}{|c|}{ BELUM } \\
\hline & & & BAP & $\%$ & BLM & $\%$ \\
\hline 1. & Kota Jambi & 18 & 16 & 88,89 & 2 & 11,11 \\
\hline 2. & Muaro Jambi & 17 & 10 & 58,82 & 7 & 41,18 \\
\hline 3. & Batang Hari & 18 & 7 & 38,89 & 11 & 61,11 \\
\hline 4. & Tebo & 19 & 10 & 52,63 & 9 & 47,37 \\
\hline 5. & Bungo & 16 & 11 & 68,75 & 5 & 31,25 \\
\hline 6. & Sarolangun & 21 & 6 & 28,57 & 15 & 71,43 \\
\hline 7. & Merangin & 22 & 12 & 54,55 & 10 & 45,45 \\
\hline 8. & Kerinci & 13 & 7 & 53,85 & 6 & 46,15 \\
\hline 9. & Tanjab Barat & 20 & 9 & 45,00 & 11 & 55,00 \\
\hline 10. & Tanjab Timur & 20 & 8 & 40,00 & 12 & 60,00 \\
\hline & JUMLAH & 184 & 96 & 52,99 & 88 & 47,01 \\
\hline
\end{tabular}

\section{Pembahasan}

Ada beberapa alasan dan faktor yang menyebabkan lembaga pendidikan yang dikelola oleh Kementerian Agama, khususnya di Provinsi Jambi terutama madrasah-madrasah belum teralisasi untuk terakrditasi, jika pun terakreditasi oleh Badan Akreditasi Sekolah/ Madrasah Provinsi Jambi, akreditasinya kebanyakan pada level peringkat (C), bahkan tidak terakreditasi.

Hasil wawancara dengan Kepala Bidang Mapenda Kementerian Agama Provinsi Jambi, Kepala Seksi Mapenda Kementerian Agama Kabupaten/Kota, Asesor dan sebagian Kepala Madrasah umumnya disebabkan, sebagai berikut:

a. Sosialisasi

Terbatasnya pengetahuan dan pemahaman akan pentingnya akreditasi dan manfaat akreditasi madrasah di kalangan Kepala Madrasah, menjadi penyebab lemahnya kesadaran untuk 
melakukan persiapan diakreditasi madrasah-madrasah. Bahkan ada keengganan untuk dilakukan visitasi dengan berbagai alasan diantarnya, misalnya: takut jika dilakukan visitasi akan mengangkat keburukan kepemimpinan Kepala Madrasah, munculnya penggunaan kesalahan dalam keuangan, manajemen pengelolaan madrasah, kurangnya prasarana pendunkung dan lain-lain.

Kegiatan sosialisasi yang dilakukan Badan Akreditasi Provinsi Sekolah/Madrasah, menjadi bagian penting untuk diikuti oleh kepala Madrasah yang biasanya didahului dengan pengiriman surat kepada kepala madrasah untuk mengikuti kegiatan sosialisasi. Di dalam kegiatan sosialisasi dipaparkan tentang mekanisme syarat pengajuan untuk dilakukan akreditasi dan tata cara pelaksanaan akreditasi.

Problem utama yang terjadi dalam kegiatan sosialisasi diantaranya: (a) seharusnya kepala madrasah yang semestinya hadir, kenyataannya diwakilkan dengan Tata usaha (TU) madrasah, atau terkadang diwakilkan dengan salah salah seorang guru, (b) terlambat datangnya surat undangan sosialisasi, berakibat tidak adanya perwakilan pengelola madrasah yang hadir pada saat sosialisasi, (c) ada madrasah yang memang tidak mau diakreditasi, semata-mata ketidaktahuan/mengerti tentang akreditasi, (d) kondisi madrasah tidak layak untuk diakreditasi.

b. Anggaran yang terbatas

Sejak Dewan Akreditasi Madrasah (DAM) Kementerian Agama RI bergabung ke dalam Badan Akreditasi Provinsi Sekolah/ Madrasah(BAP-S/M), menjadisatu-satunyalembagaindependen yang melakkukan proses akreditasi baik sekolah dilingkungan Kementerian Pendidikan \& Kebudayaan dan madrasah di lingkungan Kementerian Agama RI.

Konsekwensi bergabungnya Dewan Akreditasi Madrasah (DAM) ke Badan Akreditasi Provinsi Sekolah/madrasah (BAP S/M), maka anggaran biaya pelaksanaan akreditasi berasal dari dana Anggaran Pelaksanan Biaya Negara (APBN). Besar-kecilnya quota berapa jumlah madrasah yang akan diakreditasi, sangat tergantung pendataan yang dilakukan Kepala Seksi Mapenda Kementerian Agama Kabupaten/Kota. 
Hasil pendataan inilah kemudian menjadi pertimbangan untuk selanjutnya, madrasah tersebut diusulkan untuk diakreditasi oleh Badan Akreditasi Provinsi Sekolah/Madrasah melalui Unit Pelaksana Akreditasi (UPA) Kabupaten/Kota yang anggotanya terdiri dari unsur dari Kementerian Agama Kabupaten/Kota. Untuk itu, agar quota madrasah bisa diakreditasi dalam jumlah banyak, dan porsianggarancukup untuk menempatkan madrasah dapat diakreditasi, maka perlunya pengetahuan pemahaman Kepala Madrasah dan guru-guru tentang pentingnya akreditasi madrasah.

c. Kondisi Geografis

Kondisi geografis dan letak wilayah dimana posisi madrasah berada, umumnya madrasah berada lingkungan yang jauh dari lokasi pemukiman penduduk. Akan mempengaruhi akses informasi yang diperlukan oleh madrasah untuk melakukan persiapan-persiapan akreditasi. Di samping problem di atas, tak kalah menjadi persoalan akreditasi madrasah adalah kondisi alam dan jarak antar madrasah, misalnya: (a) letak madrasah yang terlalu jauh dan sulitnya akses jalan mengakibatkan terhambatnya proses akreditasi, dan umumnya madrasah-madrasah berada agak jauh dari pemukiman penduduk, (b) sulitnya akses jalan berimplikasi pada terbatasnya informasi dan komunikasi, (c) kondisi cuaca dan alam sekitar yang tidak memungkinkan proses akreditasi dilakukan.

d. Jaringan antar Madrasah

Salah satu di antara kendala utama madrasah belum dapat melakukan akreditasi, adalah lemahnya kerjasama antar madrasah. Penting dilakukan membangun kerjasama antar madrasah untuk saling memberi informasi, misalnya: (a) pengalaman Kepala Madrasah yang telah berhasil membina madrasah dan melaksanakan akreditasi dengan hasil peringkat (A), (b) melakukan pertemuan secara terjadwal membahas tentang meningkatkan kualitas madrasah, (c) menerbitkan/ mengelola majalah/jurnal pendidikan sebagai media informasi.

e. Kebijakan

Kebijakan Kementerian Agama Republik Indonesia yang telah mengalokasikan anggaran dana untuk akreditasi madrasah 
tahun 2013 sebesar Rp. 370.000 .000 (tiga ratus tujuh puluh juta rupiah) khususnya di Kementerian Agama Provinsi Jambi patut diapresiasi. Untuk pelaksanaan akreditasi madrasah tahun 2013 melalui anggaran Kementerian Agama Provinsi Jambi baru dimulai bulan September-Oktober 2013 (ketika data ini ditulis hasil akreditasi madrasah 2013 belum dapat dilaporkan). (Sumber Data, Kasi Mapenda Kamenag Provinsi Jambi. Agustus 2013).

Selama ini, sebelum 2013 Kementerian Agama Provinsi Jambi masih mengandalkan dana APBN melalui Kementerian Pendidikan Nasional untuk akreditasi madrasah. Artinya, selama ini posisi madrasah sangat tergantung Kebijakan Badan Akreditasi Provinsi Sekolah/Madrasah dalam mendistribusikan sebaran berapa jumlah madrasah yang akan diakreditasi. Hasil wawancara penulis dengan beberapa orang asesor dari Kementerian Agama, menyatakan bahwa: ada kecendrungan porsi (quota) sekolah/madrsah yang akan diakreditasi melalui alokasi APBN, lebih banyak lembaga-lembaga pendidikan yang dikelola Kementerian Pendidikan \& Kebudayaan Republik Indonesia ketimbang lembaga-lembaga pendidikan yang dikelola Kementerian Agama Republik Indonesia.

\section{Kesimpulan}

Hasil penelitian berdasarkan kajian temuan dan pembahasan tentang, dapat ditarik beberapa kesimpulan, sebagai berikut:

1. Hasil akreditasi madrasah berdasakan prosentasi realisasi sampai tahun 2012, yaitu sebagai berikut: (a) 244 Raudhatul Atfhal: yang sudah diakreditasi 169 (71,63\%), yang belum 75 (28,37\%), (b) 263 Madrasah Ibtidaiyah: yang sudah terakreditasi 171(61\%), yang belum terakreditasi 92 (38,20\%), (c) 345 Madrasah Tsanawiyah: sudah terakreditasi 158 (44,99\%), belum terakreditasi 187 (55,01\%), dan (d) 184 Madrasah Aliyah: sudah terakreditasi 80 (47,01\%), dan belum terakreditasi 96 (52,99\%). Data Kementerian Agama Provinsi Jambi per-Agustus 2013, total keseluruhan madrasah yang diakreditasi Badan Akreditasi Provinsi (BAP S/M) Jambi, $450(43,44 \%)$ madrasah, sedang yang belum diakreditasi 586 $(56,56 \%)$ madrasah.

2. Problemutama pelaksanaanakreditasimadrasah, antaralainyaitu: (a) sosialisasi yang belum maksimal diterima oleh sebagian besar 
Kepala madrasah. Mengakibatkan penafsiran dan pehamanan yang beragam akan manfaat dan nilai pentingnya akreditasi madrasah, sehingga masih ditemui/dijumpai akreditasi terkesan hanya untuk membuka kelemahan/keburukan madrasah, (b) anggaran yang terbatas. Karena madrasah memperoleh quata (jatah) akreditasi dari BAP S/M Jambi melalui APBN, dan harus terbagi dengan sekolah-sekolah yang dikelola Kementerian Pendidikan Nasional, maka jatah madrasah yang mendapat kesempatan untuk diakreditasi juga hanya sedikit sekali, (c) kondisi geografis. Faktor alam dan lokasi madrasah yang umumnya berada jauh dari pemukiman penduduk menjadi pertimbangan sulitnya untuk melaksanakan akreditasi, (d) jaringan antar madrasah. Belum maksimalnya bangunan dan jalinan komunikasi dan interaksi antar kepala madrasah menjadi penyebab lemahnya nilai tawar dan partisipasi madrasah. Jalinan komunikasi hanya bersifat insidental, dan tidak terprogram/ terjadwal secara kontinu, (f) kebijakan. Kebijakan mestinya dibarengi komitmen yang kuat untuk melaksanakan akreditasi, sehingga yang menopang kesuksesan pelaksanaan akreditasi. Hasil pemeringkatan akreditasi madrasah sebagai perbandingan hasil akreditasi tahun 2007 disaat awal bergabungnya lembaga pendidikan dikelola Kementerian Agama, khusus madrasahmadrasah di Provinsi Jambi yang di akreditasi oleh Badan Akreditasi Provinsi Jambi (BAP S/M), dari data memperlihatkan hasil, yaitu: 527 madrasah memperoleh quota (jatah) diakreditasi dengan perincian: (a) Raudhatul Athfal (RA) 104 buah, dengan peringkat, 1 madrasah akreditasi A, 18 akreditasi B, 27 akreditasi C, 2 belum siap diakreditasi, dan 40 RA tanpa keterangan, (b) 251 buah Madrasah Ibtidaiyah (MI), dengan perimgkat, 0 akreditasi A, 15 akreditasi B, 6 akreditasi c, 33 belulm siap diakreditasi dan 33 tanpa keterangan, (c) 131 Madrasah Tsanawiyah, dengan peringkat: 1 akreditasi A, 21 akreditasi B, 38 akreditasi C, 48 tidak terakreditasi, 18 belum siap diakreditasi, dan 5 tabpa keterangan, (d) 42 Madrasah Alyah,dengan peringkat: 0 akreditasi A, 2 akreditasi B, 13 akreditasi C, 17 tidak terakreditasi, dan 8 tanpa keterangan. Sementara untuk 2012, Kementerian Agama Provinsi Jambi menadapt jatah 73 madrasah untuk diakreditasi melalui dana APBN dengan rincian: 3 buah Raudhatul Athfal, 
17 buah Madrasah Ibtidaiyah, 25 madrasah Tsanawiyah, dan 28 buah Madrasah Aliyah.dengan pemeringkatan sebagai berikut: (a) RA, 1 akreditasi A, 0 akreditasi B, dan 2 akreditasi C, (b) 17 buah MI, 1 akrditasi A, 5 akreditasi B, 7 akreditasi C, dan 44 tidak terakreditasi, (c) $25 \mathrm{MTs}$, dengan peringkat: 2 akrditasi A, 11 akreditasi B, 9 akreitasi C, dan 4 tidak terakreditasi, (d) $28 \mathrm{MA}$, dengan peringkat akreditasi: 0 akreditasi A, 5 akreditasi B, 15 akreditasi C, dan 8 tidak terakreditasi.

\section{Daftar Pustaka}

Abdul Rachhaman Shaleh. (2005). Madrasah dan Pendidikan Anak Bangsa Visi, Misi dan Aksi . Jakarta: Raja Grafindo Persada

Bogdan, Robert E. dan Taylor J. Steven. (1993). Kualitatif Dasar - Dasar Penelitian. (terjemahan A. Khosim Afandi) .Surabaya: Usaha Nasional.

Bogdan, Robert E. dan Bikland, Knopp.S. (1982). Qualitative Research For Education. Bostor : Allyn an Bacon Inc.

Berns, Robert. M. (2007). Child, Family, School, Community Socialization and Support. New York: Thomson Learning, Icn.

Creswell, John W. (2008). Educational Research, palnning, Conducting, and Evaluating Quantitative and Qualitative Research. USA: Prentice Hall.

Denzin, Norman. K \& Lincoln, Yvonna.S. (1994). Handbook of Qualitatif Research. New York: Sage Publication, Inc.

Feinberg, Walter. (1986). School and Society. New York: Teacher College Press.

Hasan Langgulung. (1986). Manusia dan Pendidikan suatu Analisa Psikologi dan Pendidikan. Jakarta: Al- Husna.

Husaini Usman. (2006). Manajemen Teori, Praktek dan Riset Pendidikan. Jakarta; Bumi Aksara

Lexy, J. Moleong. (1991). Metodelogy Penelitian Kualitatif. Bandung: Remaja Rosdakarya.

Leach, Jenny and Moon, Bob. (2008) The Power of Pedagogy. London: Sage Publications Ltd. 
Lincoln, Y. Vonna and Guba, Edger. G. (1985). Naturalistic Inguiry. Beverly Hill Sage Publications.

Mochtar Bochari. (2001). Pendidikan Antisipatoris. Yogyakarta: Penerbit Kanisius.

Muhaimin. (2009). Rekonstruksi Pendidikan Islam. Jakarta: Raja Grafindo

Muhaimin dan Abdul Mujib. (1993) Pemikiran pendidikan Islam Kajian Filosofis dan Kerangka Dasar Operasionalisasinya. Bandung: Trigenda Karya.

Novak, Joseph D. (1986). A Theory of Education. London: Cornell University Press.

Nurcholish Madjid. (1992). Islam Doktrin dan Peradaban. Jakarta: Yayasan Wakaf Paramadina.

Prayitno. (2009). Pendidikan Dasar Teori dan Praksis (jilid I dan II) Padang: Universitas Negeri Padang Press.

Sallis, Edward. (2011). Manajemen Mutu Terpadu Pendidikan.(Alih Bahasa Ahmad Ali Riyadi). Yogyakarta: IRCiSoD

Samsul Nizar. (2009). Sejarah Pendidikan Islam Menelusuri Jejak Sejarah Pendidikan Era Rasulullah samai Indonesia.Jakarta: Kencana Predana Media.

Sudarwan Danim. (2010). Profesionalisasi dan Etika Profesi Guru. Alfabeta: Bandung.

Syaiful Sagala. (2009). Kemampuan Profesional Guru dan Tenaga Kependidikan. Alfabeta: Bandung.

Syamsul Ma'arif. (2009). Selamatkan Pendidikan Dasar Kita. Semarang. Need's Press

Spradley, James. P. (1980) Participan Observation.United state of America: Rinehart and winston. (1997). Metode Etnografi (terjemahan Misbah Elizabeth). Yogyakarta: Tiara Wacana.

Tilaar. H.A.R. (2002). Perubahan Sosial dan Pendidikan Pengantar Pedagogik Transformatif untuk Indonesia.Jakarta: Gremedia . 
. (2008). Kebijakan Pendidikan Pengantar untuk Memahami

Kebijakan pendidikan sebagai Kebijakan Publik. Yogyakarta:

Pustaka Pelajar.

Undang-undang Sistem Penddikan Nasional Nomor 20 Tahun 2003. Jakarta: Penerbit Harvarindo.

Peraturan Pemerintah Nomor 19 Tahun 2005 tentang Standar Nasional Pendidikan.

Peraturan Mendiknas Nomor 29 Tahun 2005 tentang Badan Akreditasi Nasional Sekolah/Madrasah.

Keputusan Mendiknas Nomor 064/P/2006 tentang Pengangkatan Anggota Badan Akreditasi Nasional Perguruan Tinggi, Badan Akreditasi Nasional Sekolah/ Madrasah, dan Badan Akreditasi Nasional Pendidikan Nonformal.

Surat Edaran Dirjen Pendidikan Islam Nomor SE. DJ.l/PP.00/05/2008 tentang Akreditasi Madrasah.

Van Scotter, D. Richard, Kraft, J. Richard, Haas, D. John. (1979). Foundations of Education Social Perspectives. United States of America: Englewood Cliffs.

Winarno Surakhmad, (2009). Pendidikan Nasional Strategi dan Tragedi. Jakarta: Kompas.

Zamroni. (2003). Paradigma Pendidikan Masa Depan. Proyek Peningkatan Mutu Diknas: Jakarta 